\title{
Case reports: three novel variants in PCCA and PCCB genes in Chinese patients with propionic acidemia
}

\author{
Qi Yang ${ }^{1+}$, Hong $\mathrm{Xu}^{2+}$, Jingsi Luo ${ }^{1}$, Mengting $\mathrm{Li}^{1}$, Sheng $\mathrm{Yi}^{1}$, Qinle Zhang ${ }^{1}$, Guoxing Geng ${ }^{1}$, Shihan Feng ${ }^{1}$ and \\ Xin Fan ${ }^{1 *}$
}

\begin{abstract}
Background: Propionic acidemia (PA) is an autosomal recessive metabolic disorder caused by the deficiency of the mitochondrial protein propionyl-CoA carboxylase (PCC) and is associated with pathogenic variants in either of the two genes PCCA or PCCB. The present study aimed to identify the genetic cause of three Chinese patients with PA.

Case presentation: Three Chinese PA patients were diagnosed by using gas chromatography-mass spectrometry(GC-MS), tandem mass spectrometry (MS/MS) and molecular diagnostic methods. All patients had onset in the neonatal period. One patient died of infection and metabolic decompensation, and the other two had mild to moderate developmental delay/mental retardation. Mutation analysis of the PCCA gene identified that patient 1 carried the compound heterozygous c.1288C > T(p.R430X) and c.2002G > A(p.G668R), and patient 2 was homozygous for the c.1426C > T(p.R476X) mutation. Mutation analysis of the PCCB gene identified that patient 3 harbored the compound heterozygous mutations c.359_360del AT(p.Y120Cfs*40) and c.1398 + 1G > A. Among these mutations, three (c.1288C > T, c.359_360del AT and c.1398 + 1G > A) are novel.

Conclusions: We reported three Chinese PA patients who had PCCA or PCCB mutants. Among them, in the PCCA gene, c.1288C > T(p.R430X) was a nonsense mutation, resulting in a truncated protein. c.359_360del AT was a frameshift mutation, leading to a p.Y120Cfs*40 change in the amino acid sequence in the PCCB protein. C.1398 + $1 \mathrm{G}>\mathrm{A}$ was a splicing mutation, causing skipping of the exons 13-14. In conclusion, the novel mutations uncovered in this study will expands the mutation spectrum of PA.
\end{abstract}

Keywords: Propionic acidemia (PA), Chromatography-mass spectrometry(GC-MS), Tandem mass spectrometry (MS/ MS), PCCA and PCCB genes, Mutation

\section{Background}

Propionic academia (PA) is one of most common organic acidemias. It is inherited in an autosomal recessive fashion, and is caused by the deficiency of the mitochondrial protein propionyl-CoA carboxylase ((PCC; EC 6.4.1.3), which catalyzes the carboxylation of propionyl

\footnotetext{
* Correspondence: yangqisklmg126@126.com

${ }^{\dagger}$ Qi Yang and Hong Xu contributed equally to this work.

'Department of Genetic and Metabolic Central Laboratory, Guangxi Maternal and Child Health Hospital, No.59, Xiangzhu Road, Nanning, China Full list of author information is available at the end of the article
}

CoA to yield D-methylmalonyl-CoA [1]. Patients with PA often present with acute deterioration, cardiac arrhythmias, metabolic acidosis, dyspnea and hyperammonemia. Without prompt diagnosis and management, patients can deteriorate quickly and lapse into lethargy, seizures, or sudden death [2].

PCC, a mitochondrial biotin-dependent enzyme in the catabolic pathway of amino acids [3], is composed of an $\alpha 6 \beta 6$ structure [4]. The $\alpha$ and $\beta$ subunits are encoded by PCCA (MIM 232000) and PCCB (MIM 232050) genes

(c) The Author(s). 2020 Open Access This article is licensed under a Creative Commons Attribution 4.0 International License, which permits use, sharing, adaptation, distribution and reproduction in any medium or format, as long as you give appropriate credit to the original author(s) and the source, provide a link to the Creative Commons licence, and indicate if changes were made. The images or other third party material in this article are included in the article's Creative Commons licence, unless indicated otherwise in a credit line to the material. If material is not included in the article's Creative Commons licence and your intended use is not permitted by statutory regulation or exceeds the permitted use, you will need to obtain permission directly from the copyright holder. To view a copy of this licence, visit http://creativecommons.org/licenses/by/4.0/ The Creative Commons Public Domain Dedication waiver (http://creativecommons.org/publicdomain/zero/1.0/) applies to the data made available in this article, unless otherwise stated in a credit line to the data. 
localized on chromosomes $13 \mathrm{q} 32$ and 3q21-q22, respectively $[5,6]$. To date, more than 200 mutations in both the PCCA and PCCB genes have been reported (www. hgmd.cf.ac.uk/ac/gene.). There is a large degree of genetic heterogeneity in the PCCA gene, and no prevalent mutations have been observed in any population studied. On the contrary, in the $P C C B$ gene, there was a limited number of mutations accounting for most of the patients in different ethnic groups. Among the Japanese, c.923924insT, c.1644-6C > G and R399Q are the most common mutations [7]. There are two main types of $P C C B$ gene mutations in patients with PA in Latin America, c.1218-1231dell4insl2 and E168K, accounting for more than $60 \%$ of cases [8]. Here we reported three patients with PA who were diagnosed using gas chromatographymass spectrometry (GC-MS) and tandem mass spectrometry (MS/MS) [9]. We then identified three novel mutations in the $P C C A$ and $P C C B$ genes by Sanger sequencing.

\section{Case presentation}

\section{Affected individuals}

Three unrelated patients are from Guangxi China, and were clinically diagnosed with PA using via urine organic acid analysis by gas chromatography-mass spectrometry (GC-MS) and carnitine analysis by tandem mass spectrometry (MS/MS) (Table 1).

\section{Clinical phenotype}

All patients were born full term with normalbirth weight. Patient 1 was a boy and Patient 3 was a girl both of non-consanguineous parents. Patient 2 was a boy of first-degree-cousin parents. All patients were screened in the Genetic and Metabolic Central Laboratory affiliated to Guangxi Maternal and Child Health Hospital. The results are shown in Table 1. Propionyl glycine, 3hydroxypropionate and methyl citrate were increased in urine excretion. MS/MS showed increased of acylcarnitine profile revealed and increased C3-acylcarnitin, C3/ $\mathrm{C} 2$ and $\mathrm{C} 3 / \mathrm{C} 0$ acylcarnitine ratio.

Patient 1 was 3 weeks old when he presented with tachypnea and malignant hyperthermia, and was diagnosed with presumed sepsis. He was admitted to the hospital three times due to recurrent andrespiratory tract infections. At 6 months of age, he developed generalized tonic clonic seizures, metabolic acidosis (bicarbonate, $15.4 \mathrm{mmol} / \mathrm{L}$ ) and hyperammonemia (ammonia, $516 \mu \mathrm{mol} / \mathrm{L}$ ). Only then did he undergo the screening by MS/MS and GC-MS, and diagnosed with PA. Unfortunately, he died at six and a half months of age from sudden cardiac arrest.

Patient 2 had suffered from recurrent vomiting, lethargy and hyperventilation at the age of 1 month. Fortunately, the patient was diagnosed with PA and treated with low-isoleucine, -methionine, -threonine, and-valine diet, L-carnitine, and biotin at the first time. Thereafter, he experienced a few metabolic crises; and the result of MS/MS and GC/MS detection showed an improvement in metabolic level (Table 1). $\mathrm{He}$ underwent fundoplication and gastrostomy tube placement at age of 1.5 years for caloric intake. He is now 3 years old and has shown mild mental retardation, and his weight has increased from the 5th percentile to the 20th percentile.

Patient 3 was screened on the third day after birth. She initially received an intravenous infusion, low isoleucine, methionine, threonine and proline special formulations, as well as oral carnitine and biotin treatment. Thereafter, she had several episodes of infections, diarrhea, metabolic acidosi; and the result of MS/MS and GC/MS detection are shown in Table 1 . She is now 5 years old with moderate mental retardation. In the past few years, she has been admitted to the hospital several times due to episodes of infections,diarrhea, metabolic

Table 1 The results of MS/MS and GC/MS in neonatal period

\begin{tabular}{|c|c|c|c|c|c|c|}
\hline \multirow[t]{2}{*}{ DATE } & \multirow[t]{2}{*}{ Time } & \multicolumn{4}{|l|}{ MS/MS } & \multirow{2}{*}{$\begin{array}{l}\text { GC/MS } \\
\text { 3-Hydroxypropionate (0-1.1) }\end{array}$} \\
\hline & & $\begin{array}{l}\mathrm{CO} \\
(10-50 \mu \mathrm{mol} / \mathrm{L})\end{array}$ & $\begin{array}{l}\mathrm{C} 3 \\
(0.38-3.6 \mu \mathrm{mol} / \mathrm{L})\end{array}$ & C3/C2 (0.04-0.2) & $\mathrm{C} 3 / \mathrm{CO}(0.02-0.17)$ & \\
\hline \multirow[t]{3}{*}{ Patient 1} & At the time of diagnosis & $4.62 \downarrow$ & $8.99 \uparrow$ & $1.60 \uparrow$ & $1.94 \uparrow$ & $63.52 \uparrow$ \\
\hline & - & - & - & - & - & - \\
\hline & - & - & - & - & - & - \\
\hline \multirow[t]{3}{*}{ Patient 2} & At the time of diagnosis & $1.55 \downarrow$ & $7.19 \uparrow$ & $5.48 \uparrow$ & $4.65 \uparrow$ & $280.39 \uparrow$ \\
\hline & After 1 month of treatment & $3.22 \downarrow$ & $5.54 \uparrow$ & $3.21 \uparrow$ & $1.72 \uparrow$ & $70.55 \uparrow$ \\
\hline & Latest & $4.23 \downarrow$ & $6.13 \uparrow$ & $1.82 \uparrow$ & $1.45 \uparrow$ & $30.21 \uparrow$ \\
\hline \multirow[t]{3}{*}{ Patient 3} & At the time of diagnosis & 13.1 & $9.46 \uparrow$ & $0.77 \uparrow$ & $0.72 \uparrow$ & $26.41 \uparrow$ \\
\hline & After 3 month of treatment & 14.5 & $7.34 \uparrow$ & $0.65 \uparrow$ & $0.51 \uparrow$ & $24.63 \uparrow$ \\
\hline & Latest & 13.59 & $7.26 \uparrow$ & $0.81 \uparrow$ & $0.63 \uparrow$ & $25.12 \uparrow$ \\
\hline
\end{tabular}


Table 2 PCR primers and conditions used for mutation analysis of the PCCA gene

\begin{tabular}{|c|c|c|c|c|}
\hline Exon & Sequence $\left(5^{\prime}-3^{\prime}\right)$ & & & \\
\hline & Forword & Reverse & Product size(bp) & Annealing temperature $\left({ }^{\circ} \mathrm{C}\right)$ \\
\hline 1 & ACTAGCCCTCCAGGTCCTAG & GGAAAGCAAGCGGTGTAGC & 612 & 62 \\
\hline 2 & TATTGCCTAGAACTACATTTATTGA & ACAGTGTGGAGACGAGAAAGT & 276 & 58 \\
\hline $3-4$ & AACTTGGTGTTTITTGGTCTTAAA & GTATGTCTCACTITITCTGCTTG & 362 & 58 \\
\hline 5 & TACGACTCTATAAATGATAGGCA & CCTTTGATTTCCAGTAGCGAAT & 395 & 58 \\
\hline 6 & AAGTGTACTTATTCAAGGGCTC & AATTAAAATTCTATAATCCATCACTA & 273 & 56 \\
\hline 7 & GTGTTGGCTCAAAAACTGTTGT & TGTGTGTGTGTGTGTATATCCC & 380 & 60 \\
\hline 8 & ATGAATCGGAGGAGACAGTAG & CTTCCAGAGCAACAAGTAATCA & 271 & 58 \\
\hline 9 & ATTATTGTTTCTGCGTTATTGAAC & CATTATGCTITTGGTATCTGTTAC & 266 & 58 \\
\hline 10 & GTCTGACTCTTCTTCTCCTTCTTC & TCTAAAGGCACAACTCACAATCA & 293 & 60 \\
\hline 11 & AAATAATGTITTGAGAGGTATGTATA & CAACAGAGTGAGACCCTGTCT & 347 & 60 \\
\hline 12 & AACTITAAGAAAATGTTTATGTAATG & ATCTTAATTAACACTTTATGGAGT & 349 & 60 \\
\hline 13 & TGTGATTTTCTTGTTTGTTTCTAT & TACCTCATTGTITGGCTATACC & 295 & 60 \\
\hline 14 & TTGATTITTAAGTACATTCTAAGTTG & TCACTTGTCCTTCAATTTACACC & 365 & 60 \\
\hline 15 & TTTCCTATTTCCAGAAGTTGAA & ACTACAAACTAACATAACGCTGAA & 393 & 60 \\
\hline 16 & ATGTATTGAAAACTGAACTATCATAA & AATGTGCTGTGCCATATTCTCA & 315 & 60 \\
\hline 17 & TTAATTGATACCACAAGTTCAGATA & TCAAAATAGAGTGAAATTATGTATTAC & 362 & 60 \\
\hline 18 & AATAGATGCCCTATAAAATACTTG & ACTTCTCCAAAGACCCATAAGAT & 338 & 60 \\
\hline 19 & GATGATTCTTAGAGTAGGTGTTAA & GATGAAAAATACATAGAGGTACTAC & 367 & 60 \\
\hline 20 & AAAATGGCTGCTGCTTTGTATG & CATTAAATGCTCAGGTTAAAACTTA & 371 & 60 \\
\hline 21 & GTITITGGCTATCGTGAACATTA & CCTAGAATATCATTTGTAAAGGCA & 272 & 60 \\
\hline 22 & TGATTTAGAATGAATGCTACTITGA & CTGTTTAGGGGGCGTCGGT & 345 & 60 \\
\hline 23 & CACATATTTGGGGCATTTGACA & GTAGAAGCGAGGGGGAGAGG & 304 & 60 \\
\hline
\end{tabular}

acidosis and generalized tonic-clonic seizures. She also had poor weight gain (6th percentile). Her recent heart assessment is normal.

\section{Mutation analysis}

Peripheral blood was obtained from the patients and their parents. DNA was isolated from peripheral blood using the Lab-Aid DNA kit (Zeesan Biotech Co., Ltd., Xiamen, China) according to the manufacturer's protocol. NanoDrop ND-2000 spectrophotometer and software (NanoDrop 2000; NanoDrop Technologies; Thermo Fisher Scientific, Inc., Waltham, MA, USA) were used for DNA quality detection. Primer version 3 (frodo.wi.mit.edu) was used to design PCR primers for PCR amplification of all exons and and flanking introns of the PCCA (NM_000282.3) and PCCB genes (NM 000532.4) (Tables 2 and 3). Each $50 \mu$ primary PCR mixture contained $200 \mathrm{ng}$ genomic DNA, $2.5 \mu \mathrm{l} 10 \mathrm{X}$ buffer, $8 \mu \mathrm{l}$ of a dNTP mixture ( $2.5 \mathrm{mmol} / \mathrm{L}), 2 \mathrm{U}$ Taq DNA polymerase (Takara Biotechnology Co., Ltd., Dalian, China), $1.5 \mu \mathrm{l}(10 \mu \mathrm{mol} / \mathrm{L})$ of each prime. PCR amplification including the following steps: (1) denaturing initial: $95^{\circ} \mathrm{C}$ for $5 \mathrm{~min}$. (2) 35 cycles of $95^{\circ} \mathrm{C}$ for $30 \mathrm{~s}, 56 \sim 60^{\circ} \mathrm{C}$ for $30 \mathrm{~s}, 72^{\circ} \mathrm{C}$ for $60 \mathrm{~s}$, (3) final extension: $72{ }^{\circ} \mathrm{C}$ for 10 min. The PCR products were sequenced directly in an ABI 3500 genetic analyzer. (Thermo Fisher Scientific, Inc.).

To evaluate whether novel variants were diseasecausing mutations or polymorphisms, PolyPhen 2.0 and Mutation Taster tools were performed to analyze the functional effects of novel variants. Variants were further evaluated according to the ACMG and AMP standards and guidelines [10]. Three PCCA mutations and two $P C C B$ mutations were identified. Patient 1 was compound heterozygous for c. $1288 \mathrm{C}>\mathrm{T}$ and c. $2002 \mathrm{G}>\mathrm{A}$ changes in the PCCA gene. Heterozygous c. $1288 \mathrm{C}>\mathrm{T}$ and c. $2002 \mathrm{G}>\mathrm{A}$ mutations were identified in the father and mother, respectively. Patient 2 was homozygous for c.1426C $>\mathrm{T}(\mathrm{p} \cdot \mathrm{R} 476 \mathrm{X})$ in the PCCA gene, and his parents were heterozygous. Patient 3 was compound heterozygous for c.359_360del $\mathrm{AT}$ and c.1398+1G>A changes in the $P C C B$ gene. The heterozygous c.359_360del AT and c.1398+1G > A mutations were identified in the father and mother, 
Table 3 PCR primers and conditions used for mutation analysis of the PCCB gene

\begin{tabular}{|c|c|c|c|c|}
\hline Exon & Sequence $\left(5^{\prime}-3^{\prime}\right)$ & & & \\
\hline & Forword & Reverse & Product size(bp) & Annealing temperature $\left({ }^{\circ} \mathrm{C}\right)$ \\
\hline 1 & TGGTCAGAGAAGAGCAAGGAC & GGTTATACCCGCCTCCACG & 603 & 60 \\
\hline 2 & GCCCTTGCTITGCTTACTAAAT & AGTGTACGGTCGCTCACGC & 449 & 60 \\
\hline 3 & GCCAAACTCATTAGAAGAAGTATT & TTTCCCCAAACTACAAGCAAGT & 240 & 56 \\
\hline 4 & CTGTCTCCAGGGCTCAAGCAA & CCGCAAAGATACTCAATAAGCAC & 447 & 60 \\
\hline 5 & CTATTAAATATCTGGTCCTTTGTC & ACAATGCGGCAGAGAACAATG & 410 & 58 \\
\hline 6 & TGTTATCTTATTGTTGTCTTTATCT & ACACCTTATCATCACTATGCTG & 332 & 58 \\
\hline 7 & GCTGAATCAACTCTAAGGCTGT & CAGTCTTCCCAAATAAGGTCTG & 301 & 60 \\
\hline 8 & AAGGTATGTATTATGTGGCATTAC & AAGGTATGTATTATGTGGCATTAC & 350 & 60 \\
\hline 9 & CGTGTCACCCCATTTCCTTTC & CGTGTCACCCCATTTCCTTTC & 249 & 58 \\
\hline 10 & AGTGTCATTACATCTTATACTTGTC & ATTTAGATTTTTCCTCTGGTCAT & 314 & 56 \\
\hline $11-12$ & GGATGGCTGCTGAGGACAAAT & CTGCGGGGCTGGGAACAAC & 691 & 60 \\
\hline 13 & TAGGGCTATTCTTGTTCTTTGTC & GGAGACTTACCAAGGTCTAGGT & 358 & 60 \\
\hline 14 & CCCACACACAGTGATAATGAGTT & CAAAGGCAAAAAGGCAGTTATGT & 276 & 60 \\
\hline 15 & CTGAGCAGAAGGTTGAGGGGT & ATTAGGAGATAGATAGGGCATATT & 639 & 60 \\
\hline
\end{tabular}

respectively. The novel mutations of the PCCA gen$\mathrm{e}(\mathrm{c} .1288 \mathrm{C}>\mathrm{T})$ and $P C C B$ gene(c.359_360del AT and c. $1398+1 \mathrm{G}>\mathrm{A}$ ) were not detected in any of the 200 normal controls (600 alleles) enrolled in this study. According to the ACMG standards and guidelines for the interpretation of sequence variants, these novel mutations are pathogenic. Clinical findings and genotypes are summarized in Table 4 and Fig. 1.

\section{Discussion and conclusions}

In China, increasing numbers of patients with genetic metabolic deficiencies are being diagnosed and treated in the neonatal period [11]. However, in terms of managing PA patients, it is different from those countries where newborn screening for these disorders is freely available. Some cases will only seek medical attention if intoxication has appeared. In this study, although all PA cases presented in an acute neonatal form, patient 1 and 2 were diagnosed with PA, after presenting clinical symptoms, and not through neonatal screening. Patient 1 initially presented with tachypnea and malignant hyperthermia, and was diagnosed with presumed sepsis. At that time, the patient's relevant metabolic levels (such as blood ammonia level) were not measured. This resulted in a delay in reaching until an accurate diagnosis, during which the patient developed generalized tonic clonic seizures, metabolic acidosis and hyperammonemia. The patient died at six and a half months of age from sudden cardiac arrest. Patient 2 was diagnosed by metabolite screening at the first time after symptoms appeared. After treatment, the prognosis was good.
Newborn screening is a very important means of reducing the burden and the mokrtality rate of the disease [12].

In this study, we identified three different mutations in the PCCA gene and two different mutations in the $P C C B$ gene. Patient 1 was compound heterozygous for c. $1288 \mathrm{C}>\mathrm{T}$ and c. $2002 \mathrm{G}>\mathrm{A}$ changes in the $P C C A$ gene. The c.2002G $>$ A(p.G668R) mutation has been previously reported [13], that is maps to the biotinylation domain, and it is defective in biotin binding [14]. The other mutation c. $1288 \mathrm{C}>\mathrm{T}$ has been reported in the Genome Aggregation Database as a SNP (rs776821944); however, the frequency of the variant only in genome aggregation was 0.000008/1, and was reported to be of no clinical significance. The mutation of c.1288C $>$ T (p.R430X) is located in biotin carboxylation domain of the PCC enzyme and causes a premature termination codon, resulting in a truncated protein that undergoes nonsense-mediated decay (NMD) $[15,16]$. According to the ACMG standards and guidelines for the interpretation of sequence variants, the mutation of $\mathrm{c} .1288 \mathrm{C}>\mathrm{T}(\mathrm{p} . \mathrm{R} 430 \mathrm{X})$ is pathogenic. The homozygous mutation c.1426C $>\mathrm{T}(\mathrm{p} . \mathrm{R} 476 \mathrm{X})$ in the PCCA gene identified in Patient 2 was firstly reported in Indian patients [2]. Deepti Gupta et al. demonstrated that the nonsense mutation c.1426C > T(p.R476X) could form truncated proteins that undergo NMD [17]. The mutations of c.2002G > A(p.G668R), c.1288C > T (p.R430X) and c.1426C > T(p.R476X) impact the structure of the $\alpha$ subunit and reduced the activity of the PCC enzyme to varying degrees, leading to a variable phenotypes in patients. Patient 3 was compound heterozygous for 
Table 4 Summary of the clinical features and genotypes of the patients with propionic acidemi

\begin{tabular}{|c|c|c|c|c|c|c|}
\hline \multirow{2}{*}{$\begin{array}{l}\text { Patient } \\
\text { NO }\end{array}$} & \multirow[t]{2}{*}{ Gender } & \multicolumn{2}{|l|}{ Mutations } & \multirow{2}{*}{$\begin{array}{l}\text { Onset } \\
\text { Diagnosis }\end{array}$} & \multirow[t]{2}{*}{ Current age } & \multirow[t]{2}{*}{ Outcome } \\
\hline & & Paternal & Maternal & & & \\
\hline \multicolumn{7}{|l|}{ PCCA } \\
\hline 1 & M & c.2002G > A(p.G668R) & c.1288C > T(p.R430X) & $21 d$ & Died at $6.5 \mathrm{~m}$ & Epilepsy, possible cardiomyopathy \\
\hline 2 & $\mathrm{~F}$ & c.1426C > T(p.R476X) & c.1426C > T(p.R476X) & 1 mon & $3 y$ & Mild mental retardation, normal growth \\
\hline \multicolumn{7}{|l|}{ PCCB } \\
\hline 3 & M & $\begin{array}{l}\text { c.359_360delAT } \\
\text { (p.Y120Cfs*40) }\end{array}$ & C. $1398+1 G>A$ & $3 d$ & $5 y$ & $\begin{array}{l}\text { Moderate mental retardation, epilepsy, } \\
\text { growth failure }\end{array}$ \\
\hline
\end{tabular}

c.359 360delAT and c.1398 + 1G > A mutations in the $P C C B$ gene. To the best of our knowledge, c.359_ 360delAT(p.Y120Cfs*40) and c.1398+1G >A in the $P C C B$ gene are novel mutations. These mutants were not present in the HGMD (http://www.ncbi.nlm.nih.gov), ClinVar(http://www.hgmd.cf.ac.uk/ac/), dbSNP (http:// www.ncbi. nlm.nih.gov/SNP) or the 1000 Genomes databases (http://browser.1000genomes.org/index.html). The variant c.359_360delAT(p.Y120Cfs*40) caused a frameshift alteration after codon 120 leading to a premature termination codon (PTC) which is located at codon 160, resulting in truncation of the PCCB protein, thus, leading to a loss of function. A similar splicing mutation (c.1398 $+1 \mathrm{G}>\mathrm{T}$ ) has been reported to be associated with $\mathrm{PA}$. The splicing mutation c. $1398+1 G>T$ in the $P C C B$ gene results in exons 13-14 being skipped, leading to a novel aberrant aberrant transcripts [17]. We propose that our novel variant $(c .1398+1 \mathrm{G}>\mathrm{A})$ acts in the same manner. The splice site mutation (c.1398+1G > A) is expected to eliminate splicing following exon 13, and causes exons 13-14 skipping, leading to aberrant splicing of the transcript. The CoA carboxyl transferase $\mathrm{N}$ terminal and C-terminal form the active site of the
PCCB subunit where c.359 360delAT(p.Y120Cfs*40) and $c .1398+1 G>T$ are part of the active site and thus predicted to affect the catalysis or substrate binding. Therefore, according to the ACMG standards and guidelines for the interpretation of sequence variants, the mutations of c.359_360delAT(p.Y120Cfs*40) and c. $1398+1 G>A$ are pathogenic. To date, of all mutations in PCCB described in patients, phenotypic severity has been observed to differ in patients with biallelic nonsense, deletion, or null mutations, which may be related to differences between individuals in NMD activity and NMD efficiency. Splice site variants are also seen, and, in general, result in milder disease [18]. Therefore, our patients exhibit a varying degrees of phenotype, which may be due to differences in protein activity, expression, and timely treatment.

In summary, we report $3 \mathrm{PA}$ patients and the molecular basis of their disease were identified by PCRsequencing of all coding exons of the PCCA and PCCB genes. Three novel mutations, c.1288C $>\mathrm{T}$ (p.R430X) in the PCCA gene, c.359_360delAT(p.Y120Cfs*40) and c.1398+1G > A in the PCCB gene, were identified. The present study will expand the mutation spectrum of PA.

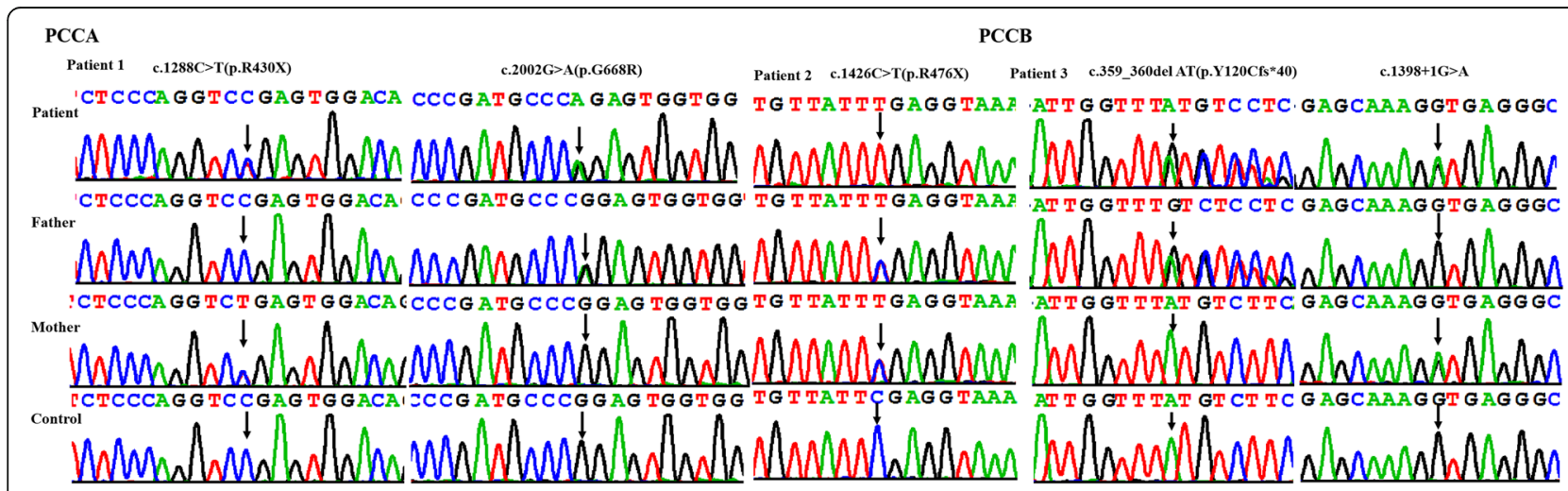

Fig. 1 DNA sequencing result from PCCA (Patient1-2) and PCCB (Patient3) gene, changes also seen in the father or/ and mother, but not seen in a representative normal subject. Three novel mutations: c.1288C > T(p.R430X) (PCCA, patientv1); c.359_360delAT(p.Y120Cfs*40) (PCCB, patient 3), c.1398 + 1G > A (PCCB, patient 3) 


\section{Abbreviations}

PA: Propionic acidemia; GC-MS: Gas chromatography-mass spectrometry; MS/ MS: Tandem mass spectrometry; PCC: Propionyl-CoA carboxylase

\section{Acknowledgements}

We are grateful to the family for participating in this study.

\section{Authors' contributions}

QY and XF designed the study and drafted the manuscript; HX, QY, JSL, MTL and SY extracted, analyzed, interpreted the data, and collected the clinical data; QLZ, HX, GXG and SHF performed the targeted sequencing, analyzed and interpreted the data; HX and QY participated in the study coordination and revised the manuscript. All authors read and approved the final version of the manuscript.

\section{Funding}

This research was supported by Guangxi Natural Science Foundation under Grant No. 2016GXNSFBA380191, which has been used for validation of the pathogenicity of identified variants. The funders are not involved in the study design, data collection and analysis, performing experiments and in writing the manuscript.

\section{Availability of data and materials}

The datasets generated and analysed during the current study are available in the Mendeley repository, https://data.mendeley.com/datasets/dk3 pfbb8f5/3 (DOl: https://doi.org/10.17632/dk3pfbb8f5.3).

\section{Ethics approval and consent to participate}

All procedures in this study were approved by the Institutional Review Boards and Ethics Committees of Guangxi Maternal and Child Health Hospital. Detailed written informed consent was obtained from all participants. For the patients who are underage, written informed consent for participation in this study was obtained from the patients' parents or guardians.

\section{Consent for publication}

The parents of the three children (under 18) has signed written informed consent for publication of clinical and genetic data.

\section{Competing interests}

The authors declare that they have no competing interests.

\section{Author details}

${ }^{1}$ Department of Genetic and Metabolic Central Laboratory, Guangxi Maternal and Child Health Hospital, No.59, Xiangzhu Road, Nanning, China. ${ }^{2}$ NanNing Region Center for Disease Prevention and Control, No.55, Xiangzhu Road, Nanning, China.

Received: 14 November 2019 Accepted: 23 March 2020

Published online: 06 April 2020

\section{References}

1. Fenton WA, Gravel RA, Rosenblatt DS. Disorders of propionate and methylmalonate metabolism. In: Scriver CR, Beaudet AL, Sly WS, Valle D, editors. The metabolic and molecular bases of inherited disease. New York: McGraw-Hill; 2001. p. 2165-204.

2. Wolf B, Hsia YE, Sweetman L, Gravel R, Harris DJ, Nyhan WL. Propionic acidemia: a clinical update. J Pediatr. 1981:99:835-46.

3. Gallego-Villar L, Pérez-Cerdá C, Pérez B, Abia D, Ugarte M, Richard E, et al. Functional characterization of novel genotypes and cellular oxidative stress studies in propionicacidemia. J Inherit Metab Dis. 2013;36:731-40.

4. Haase FC, Beegen H, Allen SH. Propionyl-coenzyme A carboxylase of Mycobacterium smegmatis. An electron microscopic study. Eur J Biochem. 1984;140:147-51.

5. Kraus JP, Firgaira F, Novotný J, Kalousek F, Williams KR, Williamson C, Ohura T, Rosenberg LE. Coding sequence of the precursor of the beta subunit of rat propionyl-CoA carboxylase. Proc Natl Acad Sci U S A. 1986:83:8049-53.

6. Lamhonwah AM, Barankiewicz TJ, Willard HF, Mahuran DJ, Quan F, Gravel RA. Isolation of CDNA clones coding for the alpha and beta chains of human propionyl-CoAcarboxylase: chromosomal assignments and DNA polymorphisms associated with PCCA and PCCB genes. Proc Natl Acad Sci U S A. 1986:83:4864-8

7. Yang X, Sakamoto O, Matsubara Y, Kure S, Suzuki Y, Aoki Y, et al. Mutation spectrum of the PCCA and PCCB genes in Japanese patients with propionic acidemia. Mol Genet Metab. 2004;81:335-42.

8. Pérez B, Angaroni C, Sánchez-Alcudia R, Merinero B, Pérez-Cerdá C, Specola $\mathrm{N}$, et al. The molecular landscape of propionic acidemia and methylmalonic aciduria in Latin America. J Inherit Metab Dis. 2010;33:S307-14.

9. Matsumoto I, Kuhara I. A new chemical diagnostic method for inborn errors of metabolism by mass spectrometry. Mass Spectrom Rev. 1996;15:43-57.

10. Richards S, Aziz N, Bale S, Bick D, Das S, Gastier-Foster J, et al. Standards and guidelines for the interpretation of sequence variants: a joint consensus recommendation of the American College of Medical Genetics and Genomics and the Association for Molecular Pathology. Genet Med. 2015; 17:405-24.

11. Wasant $P$, Vatanavicharn $N$, Srisomsap C, Sawangareetrakul $P$, Liammongkolkul S, Svasti J. Retrospective study of patients with suspected inborn errors of metabolism at Siriraj hospital, Bangkok, Thailand (19972001). J Med Assoc Thail. 2005;88:746-53.

12. Grünert SC, Müllerleile S, de Silva L, Barth M, Walter M, Walter K, et al. Propionic acidemia: neonatal versus selective metabolic screening. J Inherit Metab Dis. 2012:35:41-9.

13. Campeau E, Dupuis L, León-Del-Rio A, Gravel R. Coding sequence mutations in the alpha subunit of propionyl-CoA carboxylase in patients with propionic acidemia. Mol Genet Metab. 1999;67:11-22.

14. Clavero S, Martínez MA, Pérez B, Pérez-Cerdá C, Ugarte M, Desviat LR. Functional characterization of PCCA mutations causing propionic acidemia. Biochim Biophys Acta. 2002;1588:119-25.

15. Frischmeyer PA, Dietz HC. Nonsense-mediated mRNA decay in health and disease. Hum Mol Genet. 1999:8:1893-900.

16. Hentze MW, Kulozik AE. A perfect message: RNA surveillance and nonsensemediated decay. Cell. 1999;96:307-1.

17. Gravel RA, Akerman BR, Lamhonwah AM, Loyer M, Léon-del-Rio A, Italiano I. Mutations participating in interallelic complementation in propionic acidemia. Am J Hum Genet. 1994:55:51-8.

18. Richard E, Desviat LR, Perez B, Perez-Cerda C, Ugarte M. Three novel splice mutations in the PCCA gene causing identical exon skipping in propionic acidemia patients. Hum Genet. 1997;101:93-6.

\section{Publisher's Note}

Springer Nature remains neutral with regard to jurisdictional claims in published maps and institutional affiliations.
Ready to submit your research? Choose BMC and benefit from:

- fast, convenient online submission

- thorough peer review by experienced researchers in your field

- rapid publication on acceptance

- support for research data, including large and complex data types

- gold Open Access which fosters wider collaboration and increased citations

- maximum visibility for your research: over $100 \mathrm{M}$ website views per year

At BMC, research is always in progress.

Learn more biomedcentral.com/submissions 